\title{
Comparative Effect of Topical Local Anaesthetic Spray \& Gel in the Reduction of Pain on Periodontal Probing in Individuals with Untreated Chronic Periodontitis
}

\section{SARANSH SRIVASTAVA ${ }^{1}$, PRIYANKA TANDON*2}

INTRODUCTION: The experience of pain during dental procedures is a concern to many individuals. In periodontal practice, the first meet between the patient and the periodontist is usually a periodontal examination.

AIM: The present study aims to compare the efficacy of local anaesthetic gel \& spray in the reduction of pain on periodontal probing in a group of individuals with untreated chronic periodontitis.

MATERIALS AND METHODS: Thirty participants meeting the inclusion criteria were included in the study and had full-mouth periodontal probing done at six sites per tooth. The participants were divided into 2 groups: Group I;15 patients with LOX $2 \%$ gel and Group II;15 patients were assessed with lignocaine spray. Intragroup comparison was done using paired t-test and Analysis of Variance was done for inter group comparison.

RESULTS: The pre and post VAS score of the two groups over the periods were recorded of 2 minutes \& 5 minutes. In Group I, the mean VAS at 2 min decreases comparatively from the base-line \& remained lower significantly at $5 \mathrm{~min}$ as compared to the baseline. In contrast, in Group II, it decreased comparatively at 2 minutes but increases at 5 minutes and reaches almost the baseline value.

CONCLUSION: For early pain relief, study found LOX $2 \%$ gel more effective than lignocaine spray in the of untreated chronic periodontitis.

KEYWORDS: Lignocaine, Pain, Periodontitis

\section{INTRODUCTION}

Examination and evaluation of any response to periodontal therapy are measured most of all through the surrogate variable of periodontal probing depth (PD) and its derivatives (attachment loss/clinical attachment level). ${ }^{1}$ The experience of pain during dental procedures is a concern to many individuals. In periodontal practice, the first encounter between the patient and the periodontist is usually a periodontal examination. Probing of periodontal pockets to determine the extent of the disease is an essential part of this examination and may cause pain in some individuals. Periodontal probing has been reported to be a significantly painful experience for as many as 15$77 \%$ of patients with untreated periodontal disease, mainly attributable to the fact that periodontal tissues are in their most inflamed state. ${ }^{2-4}$

It is important that the periodontist at this encounter is sensitive to the discomfort level that the probing may entail.

Quantification of pain as a measurement is inherently difficult because it has both physical and psychological aspects. A common method used in pain studies is the Visual Analog Scale (VAS). It has been revealed previously to be simple to use, consistent, and valid..$^{5-6}$

Injection anaesthesia is an established method, 7 but the unwanted side effects of prolonged anaesthesia, anaesthesia of adjacent structures (lips and/or tongue) and the psychological trauma of receiving multiple invasive "injections" makes it impractical. ${ }^{8}$

Topical anaesthetics (jellies, ointments, or sprays)are preferred because they produce less post procedure numbness, but problems relating to lack of efficacy attributable to inadequate depth of penetration, uncontrolled spreading, insufficient duration of action, and difficulties of administration have limited their use. ${ }^{7,9-13}$

\section{MATERIAL AND METHODS}

The clinical trial was conducted in the Department of Periodontics, Sardar Patel Post Graduate Institute of Dental \& Medical Sciences, Lucknow, Uttar Pradesh, India. The Ethical Committee and Review Board of the Institute approved the study protocol. A total 30 subjects were selected from patients who reported to the Department of Periodontics. The protocol was clearly explained to all the patients and informed 
consent was obtained from all recruits.

Study Population: A total of 30 participants (17 males and 13 females, aged 27-71 years; mean age: $43.90 \pm 11.04$ ) meeting the inclusion criteria were included in this study and had full-mouth periodontal probing done at six sites per tooth.

Inclusion criteria were: (1). 22-71 years of age, (2). Patients with at least 20 natural teeth, (3). Patients should not have undergone SRP in previous 12 months, (4). Patients with chronic periodontitis.

Exclusion criteria were: (1). Allergy to local anesthetics, (2). Patients with coagulation disorders/or an anticoagulation therapy, (3). Patients suffering from any psychiatric disorder with chronic pain, (4). Patients taking non-steroidal anti-inflammatory drugs in 3 days before participation in the study (5). Patients having acute periodontal pain, pulpitis, abscesses, or other acute infections (6). Ulcerative lesions in the oral cavity

The 30 selected patients were divided into two groups of 15 subjects each. They are as follows:

Group I: 15 patients with LOX 2\% gel

Group II: 15 patients were assessed with LIGNOCAINE spray for reduction of pain during periodontal probing.

The following standardized materials and equipment/armamentarium were used for the purpose of study:

a). LOX 2 \% JELLY ${ }^{\circledR}$ (Lignocaine Hydrochloride Gel) (Figure 1)

b). LIDOCAINE TOPICAL SPRAY ${ }^{\mathrm{TM}}$ (Figure 2)

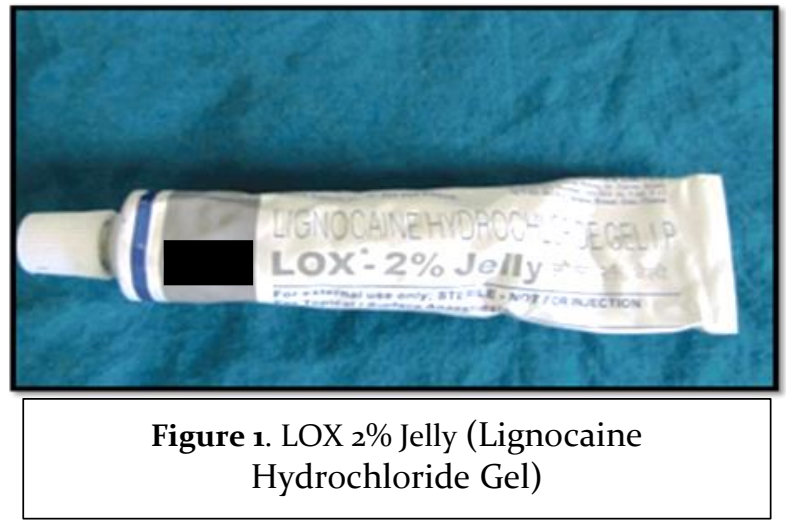

First, quadrant-wise full mouth periodontal probing at six sites per tooth was carried out using UNC 15 probe (Figure 3) and scores were recorded by Visual analog scale

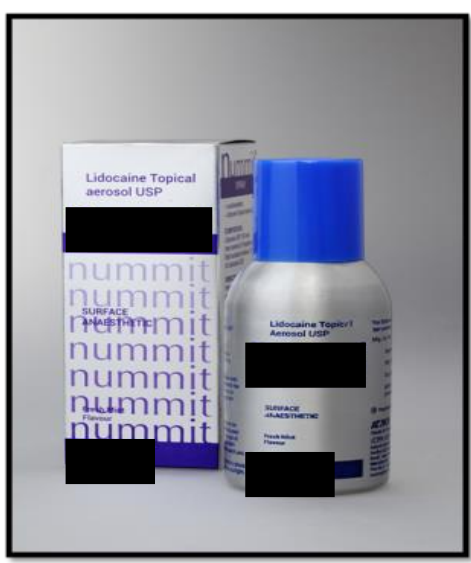

Figure 2. Lidocaine Topical Spray

(VAS). Starting with upper right quadrant, the areas were dried using a sterile gauze piece following adequate isolation with cotton rolls. In Group I LOX $2 \%$ gel was administered around each of the gingival margins of the teeth and also into the periodontal pockets with the help of syringe and was left in situ for a period of $2 \mathrm{~min}$. The gel was washed with wash spray and periodontal probing was carried out. Pain was assessed by a o-10 VAS. After completion of recording details in one quadrant, same procedure was performed on all remaining quadrants and readings were recorded.

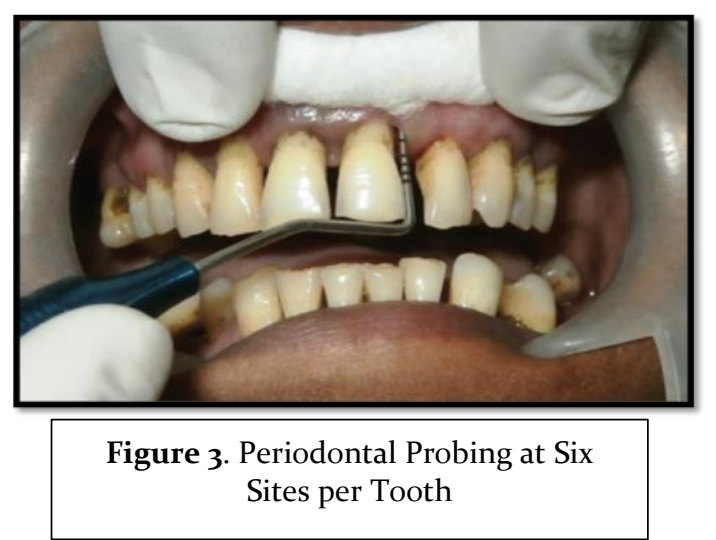

For Group II, Lidocaine Topical Spray was sprayed around the gingival margin of the teeth andalso into the periodontal pockets and was left in situ for a period of 2 min . Recording of the VAS score was similar to Group I.

To determine the efficacy of pain while during periodontal probing, the following approach was used: a). Excellent (absence of pain) - VAS score reached o. b). Good (light pain) - VAS score reached 1, 2, or 3 .

c). Unsatisfactory (moderate pain) - VAS score reached 4,5 , or 6 . 
d). Unsatisfactory (strong pain) - VAS score reached 7, 8 , or 9 .

e). Bad (intolerable) - VAS score reached 10.

Statistical Analysis: Data were summarised as Mean \pm SE (standard error of the mean). Groups were compared by repeated measures two-way analysis of variance (ANOVA) and the significance of mean difference within (intra) and between (inter)groups was done by Tukey's HSD (honestly significant difference) post hoc test. A two-tailed $(\alpha=2) \quad p<0.05$ was considered statistically significant. Analysis was performed on SPSS software (windows version 17.0).

\section{RESULTS}

The present study compares the effect of tropical local anaesthetic spray and gel in reduction of pain on periodontal probing in individual with untreated chronic periodontitis. Total 30 age and sex matched patients were randomized equally into two groups and treated with LOX $2 \%$ gel (Group I) or LIGNOCAINE SPRAY (Group II). The primary outcome measure of the study was pain (VAS score) assessed at pre -procedure (baseline) and post procedure (after 2 min and after 5 min). The objective of the study was to compare the VAS score between the groups.

The pre and post VAS score of two groups over the periods are summarised in Table 1 and Figure 4. In Group I, the mean VAS decreased significantly after the application and remained lower as compared to baseline. In contrast, in Group II, it decreased significantly at 2 minutes but increased at $5 \mathrm{~min}$ and reach almost baseline.

\begin{tabular}{|l|l|l|l|}
\hline $\begin{array}{l}\text { Time } \\
\text { period }\end{array}$ & Group I & Group II & $\begin{array}{l}\text { p } \\
\text { value }\end{array}$ \\
\hline Baseline & $5.87 \pm 0.22$ & $5.60 \pm 0.19$ & 0.933 \\
\hline $\begin{array}{l}\text { After 2 } \\
\text { min }\end{array}$ & $1.47 \pm 0.24$ & $1.93 \pm 0.15$ & 0.564 \\
\hline $\begin{array}{l}\text { After 5 } \\
\text { min }\end{array}$ & $1.80 \pm 0.17$ & $5.40 \pm 0.21$ & $<0.001$ \\
\hline
\end{tabular}

Table 1. Pre and post VAS score (Mean \pm SE, $n=15$ ) of two groups over the periods.

For each group, comparing the mean VAS score between the periods (table 2), Tukey test showed significant $(\mathrm{p}<\mathrm{o.001})$ decrease in VAS score in Group I at both post periods (after $2 \mathrm{~min}$ and after $5 \mathrm{~min}$ ) as compared to baseline but did not differ significantly ( $p>0.05$ ) between 2 min and 5 min i.e. found to be

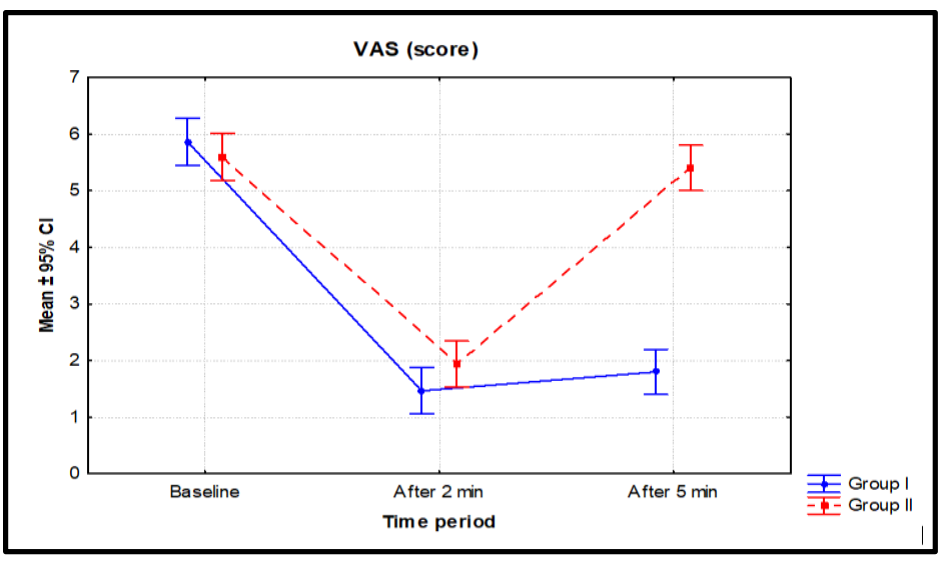

Figure 4. Mean VAS score of two groups over the periods. Vertical bar denotes 95\% CI (confidence interval) of the mean.

statistically the same. In contrast, in Group II, it decrease significantly $(\mathrm{p}<0.001)$ at 2 min but not at 5 min as compared to baseline. Conversely, in Group II, it increased significantly $(\mathrm{p}<0.001)$ at $5 \mathrm{~min}$ as compared to $2 \mathrm{~min}$.

\begin{tabular}{|c|c|c|}
\hline Comparison & Group I & Group II \\
\hline Baseline vs. After 2 min & $<0.001$ & $<0.001$ \\
\hline Baseline vs. After 5 min & $<0.001$ & 0.963 \\
\hline After 2 min vs. After 5 & 0.748 & $<0.001$ \\
\hline min & & \\
\hline
\end{tabular}

Table 2. For each group, comparison (p value) of mean VAS score between the periods by Tukey test

Similarly, for each period, comparing the mean VAS score between the periods (Table 1), Tukey test showed similar ( $p>0.05$ ) VAS score between the groups at both baseline and after $5 \mathrm{~min}$. However, at after $5 \mathrm{~min}$, it was significantly $(\mathrm{p}<0.001)$ different and higher in Group II as compared to Group I.

\section{DISCUSSION}

Studies ${ }^{13,14}$ have shown that full-mouth periodontal probing can potentially be a more painful experience compared to SRP procedures when reported using a VAS pain scoring system. The extent of periodontal inflammation related to the pain during procedure of probing. ${ }^{15}$

The LOX $2 \%$ gel used in this study contains $2 \%$ lidocaine (by weight) with the addition of a 
thermosetting agent. LOX $2 \%$ gel becomes an elastic gel at body temperature when it flows into the pocket.

The results of this study demonstrated a highly significant reduction in pain compared to baseline values as measured on VAS scale in Group I after application of LOX $2 \%$ gel.

On the other hand, lignocaine spray demonstrated less VAS score reduction compared to gels. This could be attributed to its unfavourable bioadhesion and poor possibility of the solution to confine at the preferred site. Due to its relatively weak surface anesthetic activity the onset of action is 112 seconds. Therefore 1-2 minutes of contact with the mucosa is essential.

Topical anaesthetic spray and gel have both advantages and disadvantages. The advantages of topical gels include better localization of drug in comparison with ointments and solutions, better control over systemic drug absorption, greater bioavailability and reduction indosage. ${ }^{16}$ In addition a flavoured gel is better accepted by children. ${ }^{17}$ However, gels get diluted in the mouth with time, resulting in is difficulty in maintaining prolonged mucosal contact resulting in inadequate anesthesia. ${ }^{18}$

Deepika et al. ${ }^{17}$ reported lower mean pain scores with lignocaine-dibucaine gel in comparison with benzocaine gel although statistically the difference was not significant. Topical anesthetic sprays have greater concentration of local anesthetic and are absorbed rapidly across the mucous membrane, thus providing effective anesthesia.

Nummit ${ }^{\mathrm{TM}}$ spray used in this study contains lignocaine hydrochloride in water-oil based emulsion, which increases tissue penetration and access into the nerve cell.19 However, there is difficulty in confining the effect of a drug to a small area and decreased bioadhesion thus decreasing its efficacy. ${ }^{20}$ In addition, spray has been rated as unpleasant and also may cause difficulty in swallowing in some individuals. ${ }^{21}$ Despite these disadvantages, lignocaine gel and spray are commonly used in clinical practice than adhesive patches or disks as they increase the cost of the treatment phenomenally. ${ }^{16}$

\section{CONCLUSION}

Both the LOX $2 \%$ gel \& Lignocaine spray are effective in reducing pain on periodontal probing in untreated chronic periodontitis patients.
However, LOX $2 \%$ is superior to Lignocaine spray in reducing pain for longer duration thus can be practiced as an adjunctive measure to reduce patient anxiety and attain patient cooperation.

However, further studies should be conducted to assess whether achieving any level of anesthesia and patient comfort during full-mouth probing will result in more accurate periodontal probing and to what magnitude.

\section{REFRENCES}

1. Claffey N. Decision making in periodontal therapy. The re-evaluation. J Clin Periodontol 1991;18:384-9.

2. van Steenberghe D, Garmyn P, Geers L, Hendrickx E, Maréchal M, Huizar K, et al. Patients' experience of pain and discomfort during instrumentation in the diagnosis and non-surgical treatment of periodontitis. J Periodontol 2004;75:1465-70.

3. Al-Ajmix M, Bogle G, Cole R, Rathbun E, Riggs M, Egelberg J. Ability of examiners to estimate the pain experienced by patients from probing during initial periodontal examination. J Periodontol 2005;76:985-90 4. Magnusson I, Jeffcoat MK, Donaldson D, Otterbom IL, Henriksson J. Quantification and analysis of pain in nonsurgical scaling and/or root planing. J Am Dent Assoc 2004;135:1747-54.

5. Scott J, Huskisson EC. Graphic representation of pain. Pain 1976;2:175-84.

6. Bennett K, Torrance G, Tugwell P. Methodologic challenges in the development of utility measures of health-related quality of life in rheumatoid arthritis. Control Clin Trials 1991;12 4 Suppl:118S-28.

7. van Steenberghe D, Bercy P, De Boever J, Adriaens P, Geers L, Hendrickx E, et al. Patient evaluation of a novel non-injectable anesthetic gel: A multicenter crossover study comparing the gel to infiltration anesthesia during scaling and root planing. J Periodontol 2004;75:1471-8.

8. Milgrom P, Coldwell SE, Getz T, Weinstein P, Ramsay DS. Four dimensions of fear of dental injections. J Am Dent Assoc. 1997;128:756-66

9. Friskopp J, Nilsson M, Isacsson G. The anesthetic onset and duration of a new lidocaine/prilocaine gel intra-pocket anesthetic (Oraqix) for periodontal scaling/root planing. J Clin Periodontol 2001;28:453-8.

10. Friskopp J, Huledal G. Plasma levels of lidocaine and prilocaine after application of Oraqix, a new intrapocket anesthetic, in patients with advanced periodontitis. J Clin Periodontol 2001;28:425-9.

11. Jeffcoat MK, Geurs NC, Magnusson I, MacNeill SR, Mickels N, Roberts F, et al. Intrapocket anesthesia for scaling and root planing: Results of a double-blind 
multicenter trial using lidocaine prilocaine dental gel. J Periodontol 2001;72:895-900.

12. Donaldson D, Gelskey SC, Landry RG, Matthews DC, Sandhu HS. A placebo-controlled multi-centred evaluation of an anaesthetic gel (Oraqix) for periodontal therapy. J Clin Periodontol 2003;30:171-5. 13. Magnusson I, Geurs NC, Harris PA, Hefti AF, Mariotti AJ, Mauriello SM, et al. Intrapocket anesthesia for scaling and root planing in pain-sensitive patients. J Periodontol 2003;74:597-602.

14. Karadottir H, Lenoir L, Barbierato B, Bogle M, Riggs $\mathrm{M}$, Sigurdsson T, et al. Pain experienced by patients during periodontal maintenance treatment. J Periodontol 2002;73:536-42.

15. Heft MW, Perelmuter SH, Cooper BY, Magnusson I, Clark WB. Relationship between gingival inflammation and painfulness of periodontal probing. J Clin Periodontol 1991;18:213-5.

16. Satya Bhushan NV, Nayak RN. A comparison of the efficacy of topical application of lignocaine hydrochloride 5\% gel and bupivacaine hydrochloride $5 \%$ gel for extraction of teeth. J Maxillofac Oral Surg 2010 Jun;9(2):119-126

Source of support: Nil, Conflict of interest: None declared
17. Deepika A, Rao CR, Vinay C, Uloopi KS, Rao VV. Effectiveness of two flavored topical anesthetic agents in reducing injection pain in children: a comparative study. J ClinPediatr Dent 2012 Fall;37(1):15-18.

18. Hersh EV, Houpt MI, Cooper SA, Feldman RS, Wolff MS, Levin LM. Analgesic efficacy and safety of an intraoral lidocaine patch. J Am Dent Assoc 1996 Nov;127(11):1626-1634.

19. Meechan JG. Intraoral topical anesthesia. Periodontology 2000, 2008 Feb;46(1):56-79.

20. Tulga F, Mutlu Z. Four types of topical anesthetic agents: evaluation of clinical effectiveness. J ClinPediatr Dent 1999 Spring;23(3):217-220.

21. Haasio J, Jokinen T, Numminen M, Rosenberg PH. Topical anesthesia of gingival mucosa by $5 \%$ eutectic mixture of lignocaine and prilocaine or by $10 \%$ lignocaine spray. $\mathrm{Br} \quad \mathrm{J}$ Oral Maxillofac Surg 1990;28(2):99-101. 